\title{
Cystic Fibrosis and Beckwith-Wiedemann Syndrome: A Case Report
}

\author{
Claudia Aguiar ${ }^{\mathrm{a}, \mathrm{c}}$, Liane Correia-Costa ${ }^{\mathrm{a}}$, Paulo Eden ${ }^{\mathrm{a}}$, Luisa Guedes-Vaz ${ }^{\mathrm{b}}$
}

\begin{abstract}
Cystic fibrosis (CF) is a hereditary disease of exocrine gland function that involves multiple systems but chiefly results in chronic respiratory infections, the major cause of death, pancreatic enzyme deficiency and severe malnutrition, mostly in untreated patients. The association between CF and other inherited diseases or congenital anomalies is rare. We describe for the first time the association of $\mathrm{CF}$ and Beckwith-Wiedemann syndrome (BWS). BWS is a genetic disorder commonly characterized by overgrowth. The most common features of BWS include macrosomia, macroglossia, abdominal wall defects, an increased risk for childhood tumors, kidney abnormalities, hypoglycemia in the newborn period and unusual ear creases or pits.
\end{abstract}

Keywords: Cystic fibrosis; Beckwith-Wiedemann syndrome; Genetic diseases

\section{Introduction}

Cystic fibrosis (CF; OMIM 219700) is an autosomal recessive disorder caused by mutations in the cystic fibrosis transmembrane conductance regulator (CFTR) gene, which encodes a protein expressed in the apical membrane of exocrine epithelial cells [1-4]. These mutations result in dysfunction of the apical membrane CFTR protein, affecting the chloride and sodium transport in secretory epithelial cells with abnormal ion concentrations across the apical membranes of these cells. CFTR dysfunction results in ionic imbalance of epithelial secretions in several organs, such as pancreas, gastrointestinal tract, liver, reproductive and respiratory systems. So the clinical manifes-

\footnotetext{
Manuscript accepted for publication October 09, 2014

aPediatric Department, Hospital Pediatrico Integrado, Centro Hospitalar Sao Joao, Porto, Portugal

bDivision of Pediatric Pneumology, Hospital Pediatrico Integrado, Centro Hospitalar Sao Joao, Porto, Portugal

${ }^{\mathrm{c} C}$ Corresponding Author: Claudia Aguiar, Pediatric Department, Hospital Pediatrico Integrado, Centro Hospitalar Sao Joao, 4200-319 Porto, Portugal. Email: claudiaccmaguiar@gmail.com
}

doi: http://dx.doi.org/10.14740/jocmr2003w tations include progressive pulmonary damage leading to respiratory failure, pancreatic dysfunction, liver disease that may progress to cirrhosis, gut motility problems, male infertility and high sweat electrolytes [1-3, 5, 6].

Simultaneous occurrence of $\mathrm{CF}$ and other inherited diseases or congenital anomalies has been seldom described [7]. We report a case of a 11-year-old girl with the diagnosis of CF and Beckwith-Wiedemann syndrome (BWS; OMIM 130650). This is a rare overgrowth disease that is characterized by prenatal and postnatal macrosomia, macroglossia and abdominal wall defects. Other signs are neonatal hypoglycemia, hemihyperplasia, ear anomalies, cleft palate, polydactyly, visceromegaly, renal abnormalities, adrenocortical cytomegaly, an increased risk of embryonic tumors and a positive family history [8-10]. BWS is associated with abnormalities of chromosome $11 \mathrm{p} 15$, including epigenetic changes, paternal disomy and point mutations [10-13].

\section{Case Report}

The patient is her parents' only child. They are young, Caucasian and not family related. She was born after 37 weeks of gestation, delivery by cesarean section because of macrosomia. Antenatal ultrasound at the third trimester revealed macrosomia, omphalocele, macroglossia, hepatosplenomegaly and fetal and placentar calcifications. Birth weight was 4,540 g (> 97th percentile), height of $53 \mathrm{~cm}$ (97th percentile) and head circumference $34.5 \mathrm{~cm}$ (50th - 85th percentile). Apgar score was 9 and 10 at 1 and $5 \mathrm{~min}$, respectively. At birth she presented classical BWS features.

A neonatal abdominal computed tomography (CT) scan showed also a congential malformation of pielocalicial system, with probable tubular ectasia, and renal micronodules. The correction of the omphalocele was performed at the fourth day of life. When she was 3 months old, a partial resection of the tongue was performed and at 2 years of life, she had a transcatheter intervention for treatment of patent ductus arteriosus. She had several respiratory infections with wheezing, and when she was 9 years old, she underwent lung function that showed a mixed pattern, restrictive and obstructive. She also had a thoracic CT scan with fibrotic grooves and bronchiectasis in the right upper lobe, middle lobe, lingula and superior segment of the right lower lobe. At this level some micronodules 
suggestive of infection with endobronchial dissemination or mucoid impaction were visualized. A sweat test was performed and was positive $(107 \mathrm{mmol} / \mathrm{L})$. CF genotyping results were positive for G542X/G85E mutations. In addition, the patient was found to have a severely low fecal elastase level consistent with pancreatic insufficiency.

Meanwhile, the patient who is now 11 years old, has required eight hospitalizations to manage complications of $\mathrm{CF}$, namely two pancreatitis and lung infections.

Methylation analysis of the two domains at $11 \mathrm{p} 15.5$, DMR1 (H19) and DMR2 (KCNQ1OT1) was performed by methylation-specific MLPA. Hypomethylation at DMR2 (KCNQ1OT1) and hypermetilation of DMR1 (H19) were identified. This is signal of uniparental paternal dissomy. Patogenic alterations in the analized region of CDKN1C gene were not found.

\section{Discussion}

Few reports have described the association of $\mathrm{CF}$ with other inherited or congenital diseases. These reports include association with congenital generalized hamartoma [14], infantile hypertrophic pyloric stenosis [15], intra sylvian fibroma [16], gastro-intestinal cancer [17], syringomyelia and scoliosis [18], lymphoblastic leukemia [19], sickle cell disease [7, 20-22], congenital adrenal hyperplasia [7], and Ehler's Danlos syndrome $[7,23]$. BWS

We describe for the first time the association of $\mathrm{CF}$ and

BWS is etiologically heterogeneous arising from dysregulation of one or both of the chromosome 11p15.5 imprinting centers and/or imprinted growth regulatory genes on chromosome 11p15.5. Most BWS cases are sporadic and result from loss of maternal methylation at imprinting center 2 (DMR2), gain of maternal methylation at imprinting center 1 (DMR1) or paternal uniparental disomy [11]. In this case we found an 11 p15.5 paternal uniparental disomy which corresponds to $20 \%$ of patients with BWS [24].

In Portugal, we have one CF patient in 6,000 neonates. BWS is even less frequent. The association between these two diseases is an interesting and never yet described situation. Because of the risks and everyday problems related to two severe diseases in the same patient (infections, malnutrition, possibility of malignant tumors, etc.), her management is and will be a never ending challenge.

\section{References}

1. Derichs N. Targeting a genetic defect: cystic fibrosis transmembrane conductance regulator modulators in cystic fibrosis. Eur Respir Rev. 2013;22(127):58-65.

2. Kerem E, Conway S, Elborn S, Heijerman H. Standards of care for patients with cystic fibrosis: a European consensus. J Cyst Fibros. 2005;4(1):7-26.

3. Jonsdottir B, Bergsteinsson H, Baldursson O. [Cystic fibrosis--review]. Laeknabladid. 2008;94(12):831-837.
4. Zielenski J. Genotype and phenotype in cystic fibrosis. Respiration. 2000;67(2):117-133.

5. Ratjen F, Doring G. Cystic fibrosis. Lancet. 2003;361(9358):681-689.

6. Cohen-Cymberknoh M, Shoseyov D, Kerem E. Managing cystic fibrosis: strategies that increase life expectancy and improve quality of life. Am J Respir Crit Care Med. 2011;183(11):1463-1471.

7. Banjar HH. Cystic fibrosis: presentation with other diseases, the experience in Saudi Arabia. J Cyst Fibros. 2003;2(3):155-159.

8. Calvello M, Tabano S, Colapietro P, Maitz S, Pansa A, Augello C, Lalatta F, et al. Quantitative DNA methylation analysis improves epigenotype-phenotype correlations in Beckwith-Wiedemann syndrome. Epigenetics. 2013;8(10):1053-1060.

9. Romanelli V, Meneses HN, Fernandez L, Martinez-Glez V, Gracia-Bouthelier R, M FF, Guillen E, et al. BeckwithWiedemann syndrome and uniparental disomy 11p: fine mapping of the recombination breakpoints and evaluation of several techniques. Eur J Hum Genet. 2011;19(4):416421.

10. Elalaoui SC, Garin I, Sefiani A, Perez de Nanclares G. Maternal Hypomethylation of KvDMR in a Monozygotic Male Twin Pair Discordant for Beckwith-Wiedemann Syndrome. Mol Syndromol. 2014;5(1):41-46.

11. Baskin B, Choufani S, Chen YA, Shuman C, Parkinson N, Lemyre E, Micheil Innes A, et al. High frequency of copy number variations $(\mathrm{CNVs})$ in the chromosome $11 \mathrm{p} 15$ region in patients with Beckwith-Wiedemann syndrome. Hum Genet. 2014;133(3):321-330.

12. Soejima H, Higashimoto K. Epigenetic and genetic alterations of the imprinting disorder Beckwith-Wiedemann syndrome and related disorders. J Hum Genet. 2013;58(7):402-409.

13. Choufani S, Shuman C, Weksberg R. Beckwith-Wiedemann syndrome. Am J Med Genet C Semin Med Genet. 2010;154C(3):343-354.

14. Mascaro JM, Jr., Ferrando J, Bombi JA, Lambruschini $\mathrm{N}$, Mascaro JM. Congenital generalized follicular hamartoma associated with alopecia and cystic fibrosis in three siblings. Arch Dermatol. 1995;131(4):454-458.

15. Kakish KS. Cystic fibrosis and infantile hypertrophic pyloric stenosis: is there an association? Pediatr Pulmonol. 2002;33(5):404-405.

16. Pollack LF, Hamilton RL, Fitz C, Orenstein DM. An intrasylvian "fibroma" in a child with cystic fibrosis: case report. Neurosurgery. 2000;46(3):744-747.

17. Schoni MH, Maisonneuve P, Schoni-Affolter F, Lowenfels AB. Cancer risk in patients with cystic fibrosis: the European data. CF/CSG Group. J R Soc Med. 1996;89 (Suppl 27):38-43.

18. Rusakow LS, Guarin M, Lyon RM, Splaingard ML. Syringomyelia and chiari malformation presenting as scoliosis in cystic fibrosis. Pediatr Pulmonol. 1995;19(5):317318.

19. Rizzari C, Conter V, Jankovic M, D'Angelo P, Masera G, Costantini D, Bettinelli ME, et al. Acute lymphoblastic 
leukaemia in a child with cystic fibrosis. Haematologica. 1992;77(5):427-429.

20. Warwick AB, Haver K, Rosoff PM. Homozygous sickle cell disease and cystic fibrosis in an adolescent. Pediatr Pulmonol. 1998;26(3):224-227.

21. Amendola G, Garvin J, Piomelli S. Cystic fibrosis in a black child with hemoglobin S-D disease. Am J Pediatr Hematol Oncol. 1990;12(3):340-342.
22. Porter RC, Cloutier MM, Brasfield DM, Mangos JA, Miale T, Tiller RE. Cystic fibrosis in two black children with sickle cell anemia. J Pediatr. 1979;94(2):239-240.

23. Jarish A, Giunta C, Zielen S, Konig R, Steinmann B. Sibs affected with both Ehlers-Danlos syndrome type VI and cystic fibrosis. Am J Med Gen. 1998;78:455-460.

24. Weksberg R, Shuman C, Beckwith JB. Beckwith-Wiedemann syndrome. Eur J Hum Genet. 2010;18(1):8-14. 